Rev. Interd. em Cult. e Soc. (RICS), São Luís, v. 6, n. 1, p. 45- 62, jan./jun. 2020

ISSN eletrônico: 2447-6498

\title{
A Vivência do Sagrado em Mário de Carvalho: uma Leitura Experiencial ${ }^{1,2}$
}

\section{The Experience of the Sacred in Mário de Carvalho: an Experiential Reading}

\author{
RENATA FRANÇA PEREIRA
}

Mestranda do PGLetras da UFMA

renata.franc@gmail.com

\begin{abstract}
RESUMO
Propõe-se a análise do romance Um deus passeando pela brisa da tarde, do português Mário de Carvalho, lançado em 1994. Através de pesquisa bibliográfica, foi possível desenvolver variadas linhas de análise, sendo privilegiado aqui o diálogo interdisciplinar entre a literatura e a geografia para a investigação da relação do homem com os seus entornos. Através de análise sistemática da literatura, lançamos mão da obra de teóricos expoentes nos estudos sobre o espaço, dentre os quais citamos Yi-Fu Tuan (2012 e 2013) com seus conceitos basilares de topofilia, espaço, lugar e experiência, para elucidar como se dão as relações homem-espaço no romance, evidenciando, assim, a literatura sob enfoque fenomenológico. O filósofo Gaston Bachelard (2008) traz ainda sua proposta de topoanálise para aclarar as investigações propostas acerca dos entornos da cidade fictícia de Tarcisis.
\end{abstract}

Palavras-chave: Experiência. Religiosidade. Um deus passeando pela brisa da tarde. Mário de Carvalho.

\section{ABSTRACT}

We propose the analysis of the novel A god strolling in the cool of the evening, by Portuguese writer Mário de Carvalho, published in 1994. Bibliographical research made it possible to develop several lines of work, from which we chose the interdisciplinary dialogue between literature and geography to investigate man's relationship with his surroundings. Through a systematic analysis of the literature, we have used the work of leading researchers, among which we mention Yi-Fu Tuan (2012 and 2013) with his imperative concepts of topofilia, space, place and experience, to clarify how the man-space relations in the novel come to be, thus pointing to a phenomenological approach of literature. Philosopher Gaston Bachelard (2008) also presents his proposal of topoanalysis to clarify the proposed investigations about the environments of the fictional city of Tarcisis.

Keywords: Experience. Religion phenomenon. A god strolling in the cool of the evening. Mário de Carvalho.

\section{INTRODUÇÃO}

Em pouquíssimas épocas, a temática do espaço esteve tão em voga como tem sido a partir da segunda metade do século XX. A materialização do espaço nas artes existe desde que a arte é arte, desde que a literatura é literatura, em suas tradições milenares. No entanto, quando, afinal, começou-se a pensar acerca dos entornos? Quem primeiro percebeu, sentiu o que havia fora de e em volta de si? Por mais fascinante que seja, certamente este é um registro ao qual não se tem acesso, em grande parte porque o espaço simplesmente existe. Ele existe no sentido de que, assim como todas as coisas e todas as pessoas, há uma noção primeira sobre ele que não apenas antecede, mas transcende toda e qualquer sistematização do conhecimento. Estar em determinado local implica conhecê-lo de maneira singular e

\footnotetext{
${ }^{1}$ Este artigo é um recorte da monografia apresentada ao curso de Letras da Universidade Federal do Maranhão no ano de 2019, sob orientação da Prof. Dra Márcia Manir Miguel Feitosa.

${ }^{2}$ Artigo submetido para avaliação em 10/10/2019 e aprovado em 20/10/2019.
} 
Rev. Interd. em Cult. e Soc. (RICS), São Luís, v. 6, n. 1, p. 45- 62, jan./jun. 2020 ISSN eletrônico: 2447-6498

individual, uma maneira completamente diversa da que outros conhecem este mesmo local. Ainda assim, existem noções compartilhadas sobre os locais, pois estar é também um ato social e coletivo. Isto ocorre em função da singularidade que pressupõe o ser, o estar e o próprio lugar. Subjacentes à noção de espaço, existem diversas concepções acerca dele, ou melhor, desdobramentos. Neste trabalho, traçaremos um caminho que percorre alguns desses desdobramentos.

Propõe-se neste trabalho uma pesquisa de cunho bibliográfico em que se procede ao estudo do espaço e de seus processos com vistas à compreensão de suas nuances quando de sua relação com o ser, pois "ser implica, inescapavelmente, estar em ou pertencer a algum lugar", levando em conta que "a origem da noção de lugar encontra-se no seio da vida concreta, cotidiana" e é dotada de uma nuance não reducionista, aponta Ligia Saramago (2014, p. 204, grifos da autora). Estamos falando, antes de tudo, de uma noção de espaço que é ontológica, a qual necessita ser pensada nos mais diversos contextos e campos do saber. A inquebrantável relação entre homem e espaço, ser e mundo, é materializada no termo ser-nomundo, que traduz com autenticidade as bases epistemológicas em que se apoia o nosso estudo: a fenomenologia. O método fenomenológico nos revela ser absolutamente essencial na medida em que busca a compreensão dos processos do ser-no-mundo, considerando o mundo cotidiano em sua complexidade e privilegiando a experiência humana como condição sine qua non para que essa compreensão se realize. Tal abordagem permite-nos lançar luz sobre os valores e significados atribuídos pelo homem à natureza, privilegiando a percepção, o pensamento e seus símbolos.

Para nos lançarmos a essa tarefa, tomamos como objeto de estudo a arte literária sob a forma de um romance português contemporâneo. Um deus passeando pela brisa da tarde foi escrito em 1994 por Mário de Carvalho, autor consagrado em seu ofício, embora muito menos celebrado do que deveria ser. O lisboeta de descendência alentejana soma 32 livros publicados, tendo o primeiro deles sido lançado ainda nos anos de 1980 e o último volume publicado já em 2019. À primeira leitura, o espaço não é tomado como via de análise mais óbvia, não porque lhe falta expressão, ao contrário, é uma veia demasiado pulsante e magnificente. No entanto, em se tratando de romances históricos, o que salta aos olhos é o interesse pela verossimilhança através de investigação historiográfica, ou o estudo da memória.

A relevância deste trabalho, esperamos, reside na possibilidade de lançarmo-nos a refletir sobre o ser-no-mundo no romance selecionado, levando em conta a (a)temporalidade de seus temas, seu contexto, assim como as relações que se estabelecem na obra, tomando 
Rev. Interd. em Cult. e Soc. (RICS), São Luís, v. 6, n. 1, p. 45- 62, jan./jun. 2020 ISSN eletrônico: 2447-6498

como norte o aporte teórico-metodológico da Geografia Humanista Cultural, vertente da ciência geográfica que ganhou envergadura não mais de meio século atrás. Esperamos ainda que o presente trabalho possa despertar o interesse de novos leitores para a obra de tão fascinante autor.

\section{LITERATURA E GEOGRAFIA: interfaces de conhecimento}

Existe real possibilidade de diálogo entre Ciência e Arte? É verdade que as duas coisas sejam - ou fossem -, com certa frequência, encaixotadas separadamente, postas até mesmo de maneira antagônica dentre os saberes lapidados e apreendidos pelo homem. Mas a Antiguidade nos prova que nem sempre foi assim. De fato, durante muitos séculos, foi impossível inteirar-se sobre a história de um povo sem acessar o conhecimento sobre sua cultura que, em grande parte, girava em torno de suas terras, seu cultivo e costumes relacionados a sua subsistência e ao meio. Esses saberes eram obtidos por meio da produção literária que, durante muito tempo, foi tida como a fonte privilegiada de acesso ao mundo. $\mathrm{Na}$ tradição ocidental, temos como exemplo obras gregas como tragédias e comédias, diários de viagens e navegações.

Até a instauração da era moderna, considerava-se que "o pensar filosófico estava imbricado ao que hoje designamos artístico e com o atualmente denominado científico" (2011, p. 15), numa fusão de referenciais, coloca Cláudio Benito Oliveira Ferraz em seu texto Literatura e Espaço: aproximações possíveis entre Arte e Geografia (2011). O que ocorreu, precisamente na virada do século XVIII para o século XIX, foi uma acelerada produção de saberes e inevitável mudança dos paradigmas que operavam sobre as ciências. Passou a ser admitido um modo de compreensão da natureza, do homem e do espaço pautado em uma lógica valorativa das demandas do Estado-Nação, o que levou à necessidade de se pensar as ciências sob os paradigmas das áreas matemáticas e físicas. A partir de então, Geografia e Literatura passaram a ser examinadas sob prismas científico-matemático e artístico, respectivamente.

A Geografia passou a atender às necessidades do paradigma positivista e, para acolher as demandas da sociedade industrial, transforma de maneira radical o seu método de investigação. Toda ciência precisaria "realizar um estudo preciso, rigoroso, numérico dos fenômenos sociais" (ISKANDAR; LEAL, 2002, p. 90), a fim de que uma ciência natural pudesse conquistar maior objetividade e, desta forma, se impor sobre os outros saberes, leiase: aqueles que não pudessem ser subordinados ao método de constatação dos fenômenos 
Rev. Interd. em Cult. e Soc. (RICS), São Luís, v. 6, n. 1, p. 45- 62, jan./jun. 2020 ISSN eletrônico: $2447-6498$

observáveis. Em nome deste modo de culto à ciência, a Geografia passou a preconizar uma separação sujeito/objeto e a dedicar-se a uma investigação dos aspectos "externos" do homem: "Excluded from geography are the 'internal' aspects that make people quintessentially human; namely, intention and will, ideas and symbols ${ }^{3 \%}$ (TUAN, 1978, p. $195)$.

A Geografia, ao trajar-se deste novo modo de investigação, perde muito de sua nuance abstrata. Como assimilar os conteúdos elaborados pelo imaginário, aqueles que não são obtidos através da redução matemática, rigorosamente conceitual, o conhecimento apreendido nas experiências humanas? Como elaborar referenciais espaciais sem que se lance mão das imagens apreendidas em ato, isto é, na vivência cotidiana, as quais necessitam e dependem da atribuição individual de valores e significados? O método científico positivista não é capaz de abarcar - ou legitimar - tais referenciais e, como sequela, a Geografia adormece enrijecida ao se fechar para o diálogo com outros saberes.

$\mathrm{O}$ século XX trouxe consigo uma efervescente mudança de paradigmas que nos permitem hoje propor o diálogo interdisciplinar entre saberes anteriormente apartados. Nas artes, o movimento realista do final do século XIX foi capaz de antecipar essas transformações, dando à luz suas narrativas minuciosamente descritivas do meio, dos tipos físicos, sociais e psicológicos, reavivando, assim, o interesse pelos estudos acerca das Ciências Humanas e Sociais.

Tão somente a menção da palavra "espaço" conjura, inevitavelmente, relações estreitas com a ciência que possui "a mais larga tradição em sua investigação, pensamento e exploração", conforme pontuam os geógrafos Eduardo Marandola Jr. e Lívia de Oliveira em seu estudo intitulado "Geograficidade e Espacialidade na Literatura” (2009, p. 488). As ciências, dentre elas a geográfica, como anteriormente exposto, tiveram que atravessar tumultuosas águas ao remodelar suas concepções científicas, intelectuais e culturais para que o diálogo entre Literatura e Geografia fosse possível, afinal, não se trata de associar, simplesmente, o fazer artístico ao fazer científico:

\footnotetext{
Mas pensar a relação Geografia-Literatura (...) envolve aproximar duas visões de mundo que, enquanto tais, possuem suas especificidades, virtudes e limitações. Uma aproximação simplista reduziria o potencial compreensivo de uma ou de outra. Quer dizer: ler literariamente a Geografia ou ler cientificamente a Literatura, numa transposição de discursos, produziria deformações e reduções, diminuindo assim a riqueza da interação e a sua permeabilidade. (MARANDOLA JR; OLIVEIRA, 2009, p. 488)
}

\footnotetext{
${ }^{3}$ Os aspectos que tornam as pessoas, por excelência, humanas são excluídos da geografia; nomeadamente, intenção e vontade, ideias e símbolos. (TUAN, 1978, p. 195, tradução nossa)
} 
Rev. Interd. em Cult. e Soc. (RICS), São Luís, v. 6, n. 1, p. 45- 62, jan./jun. 2020 ISSN eletrônico: $2447-6498$

Quando Yi-Fu Tuan discorre acerca das implicações metodológicas quando da pesquisa interdisciplinar em Geografia e Literatura, o geógrafo conclui:

\begin{abstract}
Literary art serves the geographer in three principal ways. As thought experiment on possible modes of human experience and relationship, it provides hints as to what a geographer might look for when he studies, for instance, social space. As artifact it reveals the environmental perceptions and values of a culture: it serves the geographer, who is also a historian of ideas. Finally, as an ambitious attempt to balance the subjective and the objective it is a model for geographical synthesis; for geography is a garden that contains the road, an art form capacious enough to include analysis ${ }^{4}$. (TUAN, 1978, p. 205)
\end{abstract}

Em última instância, é imprescindível observar que o estudo interdisciplinar exige de seu pesquisador grande cautela e sensibilidade. É frequente que nos deparemos, em textos dessa natureza, com a atribuição do termo ferramenta a um campo do saber. No entanto, a Literatura não serve de adereço aos estudos geográficos e tampouco a Geografia é um ornamento que está a serviço da obra literária. É vital que mantenhamos em mente que o diálogo interdisciplinar consiste em um processo de natureza integrativa e de ordem complementar, sem o qual é inconcebível a quebra de paradigmas e construção de novos conhecimentos.

É este sentido de proporcionar pontos de convergência entre saberes que orienta a nossa predileção pelas bases epistemológicas adotadas que alicerçam a linha de análise teórico-metodológica das investigações aqui propostas. A Geografia Humanista Cultural configura-se como uma grande confluência de saberes de que a crítica literária tem se valido para abarcar e expandir as concepções de espaço na literatura.

De base fenomenológico-existencialista, esta abordagem da ciência geográfica dá protagonismo ao estudo das relações estabelecidas entre o homem e o seu entorno, o espaço vivido. É de suma importância que seja frisado o termo "vivido", uma vez que, aqui, a compreensão da natureza humana se dá a partir das experiências que se dão nestes espaços; experiências essas que têm o poder de transformar por completo as nuances dos ditos entornos e são por isso indissociáveis do contexto espacial em que ocorrem.

\footnotetext{
${ }^{4}$ Arte literária serve ao geógrafo de três maneiras principais: como experimento intelectual dos modos possíveis de experiência e relações humanas, dá pistas de quais aspectos o geógrafo deve procurar ao estudar, por exemplo, o espaço social. Como artefato, revela os valores e percepções ambientais de uma cultura: serve ao geógrafo, o qual também é um historiador das ideias. Por fim, como tentativa ambiciosa de equilibrar o subjetivo e o objetivo, serve como um modelo para a síntese geográfica; pois, geografia é um jardim que contém a estrada, uma forma de arte suficientemente capaz de incluir análise. (TUAN, 1978, p. 200, tradução nossa)
} 
Rev. Interd. em Cult. e Soc. (RICS), São Luís, v. 6, n. 1, p. 45- 62, jan./jun. 2020 ISSN eletrônico: $2447-6498$

Nesta mesma linha segue o trabalho do geógrafo sino-americano Yi-Fu Tuan, cujos estudos são vitais para o trabalho que aqui aflora. Tuan ${ }^{5}$ é um geógrafo cuja obra sempre deixou bem pronunciada uma abordagem interdisciplinar de estudos. Muitos de seus trabalhos contêm reflexões e exemplificações das artes, da própria geografia e de saberes relacionados aos campos das ciências humanas e sociais. No decorrer de toda a sua obra, Tuan procura lançar luz sobre as experiências vividas pelo homem enquanto ser-no-mundo, colocando no centro de seus estudos as noções de valores, visões de mundo, atitudes e comportamentos como condutores da percepção que se tem dos espaços e dos significados neles construídos. Não por acaso, a grande obra de Tuan é intitulada Topofilia: um estudo da percepção, atitudes e valores do meio ambiente (2012).

No intento de investigar a natureza experiencial com a qual os espaços e lugares são percebidos e assimilados no romance de Mário de Carvalho, a contribuição de Yi-Fu Tuan se configura como basilar para o estudo das relações homem-espaço, na medida em que o autor postula a inegável importância da experiência. Em sua obra Espaço e lugar: a perspectiva da experiência, Tuan se ocupa de explicar a natureza da experiência e, em um de seus muitos conceitos, coloca:

[...] a experiência implica a capacidade de aprender a partir da própria vivência. Experienciar é aprender; significa atuar sobre o dado e criar a partir dele. O dado não pode ser conhecido em sua essência. O que pode ser conhecido é uma realidade que é um constructo da experiência, uma criação de sentimento e pensamento. (TUAN, 2013, p. 18)

A natureza intrinsecamente subjetiva dos espaços é uma noção essencial para que compreendamos quão ontológica é a essência desta abordagem geográfica de análise. Tratase, antes de tudo, de dar a devida importância ao papel da percepção na construção de significados que os sujeitos dão aos espaços, podendo ou não transformá-los em lugares. Mas afinal, como se difere o espaço do lugar? Tuan se ocupa em grande parte de sua obra de responder a esse questionamento e, lançando mão de exemplos de grande valor social e histórico, o geógrafo amplia e ao mesmo tempo eleva a discussão. Sobre as relações de espaço e lugar, Tuan coloca:

Na experiência, o significado de espaço frequentemente se funde com o de lugar. "Espaço" é mais abstrato do que "lugar". O que começa como espaço indiferenciado transforma-se em lugar à medida que o conhecemos melhor e o dotamos de valor. Os arquitetos falam sobre as qualidades espaciais do lugar; podem igualmente falar

\footnotetext{
${ }^{5}$ Yi-Fu Tuan, geógrafo premiado e Professor Emérito da Universidade de Wisconsin-Madison (EUA).
} 
Rev. Interd. em Cult. e Soc. (RICS), São Luís, v. 6, n. 1, p. 45- 62, jan./jun. 2020

ISSN eletrônico: $2447-6498$

das qualidades locacionais do espaço. As ideias de "espaço" e "lugar" não podem ser definidas uma sem a outra. A partir da segurança e estabilidade do lugar estamos cientes da amplidão, da liberdade e da ameaça do espaço, e vice-versa. Além disso, se pensamos no espaço como algo que permite movimento, então lugar é pausa; cada pausa no movimento torna possível que localização se transforme em lugar. (TUAN, 2013, p. 14)

O homem necessita da experiência íntima para conectar-se emocionalmente ao espaço; consequentemente, é essa conexão, essa afeição, sentimentos e valores atribuídos que conferem a esse espaço vivido o sentido de lugar. A este "elo afetivo entre a pessoa e o lugar ou ambiente físico" (TUAN, 2012 p. 19) Tuan deu o nome de "topofilia", outro conceito basilar nos estudos da Geografia Humanista Cultural que, embora seja constantemente associado à magnum opus de mesmo nome, é um neologismo nascido nos idos de 1957 com Gaston Bachelard em seu livro A poética do espaço ${ }^{6}$. Bachelard é filósofo de grande prestígio na esfera dos estudos acerca do espaço e fez de sua obra uma verdadeira morada da imaginação. Fenomenólogo, suas obras fundamentaram os estudos da Geografia Humanista Cultural, já que o teórico considerava o "espaço como instrumento de análise para a alma humana" (2008, p. 19). A proposta de Bachelard é uma topoanálise, que "seria então o estudo psicológico sistemático dos locais de nossa vida íntima” (2008, p. 28)

O autor usa de seu estilo excessivamente poético e faz de sua obra uma espécie de compêndio dos espaços mais recorrentes na literatura, tais como a casa, o porão, o sótão, a cabana, etc. Ao antecipar o que mais tarde seria ideia central para os estudos de Tuan, Bachelard afirma:

\footnotetext{
Vamos então nos dedicar ao poder de atração de todas as regiões de intimidade. Não há intimidade verdadeira que afaste. Xodós os espaços de intimidade se caracterizam por uma atração. Repitamos uma vez mais que seu ser é o bem-estar. Nessas condições, a topoanálise tem a marca de uma topofilia. É no sentido dessa valorização que devemos estudar os abrigos e os aposentos. (2008, p. 31)
}

Tanto Gaston Bachelard quanto Yi-Fu Tuan são responsáveis pela criação de diversos conceitos dos quais nos valemos, posteriormente, em análise. Por este motivo, optamos por não fazer sua exposição no presente capítulo, evitando assim repetições, uma vez que nosso intento é abordar cada categoria conceitual, imagem e concepção de maneira contextualizada, para que possam ser compreendidos em função dos acontecimentos da obra literária selecionada como objeto de análise.

\footnotetext{
${ }^{6}$ Originalmente intitulada La poétique de l'espace, publicada em 1957. A edição mais atual aqui utilizada é de 2008.
} 
Rev. Interd. em Cult. e Soc. (RICS), São Luís, v. 6, n. 1, p. 45- 62, jan./jun. 2020 ISSN eletrônico: $2447-6498$

Não menos importante é a contribuição do geógrafo canadense Edward Relph que, também sob influência dos estudos da Geografia Humanista, debruçou-se sobre os estudos do lugar. Em suas "Reflexões sobre a emergência, aspectos e essência de lugar" (2014), o autor compila as particularidades que considera mais importantes na compreensão do lugar, entre elas a concepção de lugar como reunião, localização, fisionomia, espírito e sentido de lugar, enraizamento, inferioridade, lar, inclusão/exclusão, construção, fabricação do lugar e, muito difundida e associada ao nome do autor, a noção de lugar-sem-lugaridade, que consiste em uma inabilidade na construção do sentido de lugaridade em determinados meios. As influências sofridas pelo autor, em sua preferência pelo estudo do lugar, resultam em uma concepção que muito se aproxima da de Tuan:

Lugar não é meramente aquilo que possui raízes, conhecer e ser conhecido no bairro; não é apenas a distinção e apreciação de fragmentos de geografia. O núcleo do significado de lugar se estende, penso eu, em suas ligações inextricáveis com o ser, com a nossa própria existência. Lugar é um microcosmo. É onde cada um de nós se relaciona com o mundo e onde o mundo se relaciona conosco. (RELPH, 2014, p. $31)$.

A contribuição de Relph é magnânima para os estudos da Geografia Humanista Cultural. Sua obra é uma das pioneiras em aliar a ciência geográfica à abordagem fenomenológica e, por esse motivo, integra a seara de estudos geográficos que nos convém destacar.

A certa altura de nossa análise, será imperativa a pormenorização dos espaços que permeiam o romance Um deus passeando pela brisa da tarde. À medida que tais espaços emergirem, evocaremos estudos e conceitos de teóricos aqui citados, assim como traremos à baila discussões de expoentes como a geógrafa Zeny Rosendahl que, baseada nos achados do historiador Mircea Eliade, nos brinda com uma geografia das religiões, a qual será de grande importância quando tratarmos, em análise, o que toca aos espaços e lugares sagrados.

\section{LÚCIO VALÉRIO E O ANTAGONISMO DO SAGRADO ROMANO}

Lúcio é duúnviro, em seu segundo mandato, da cidade fictícia e autoridade máxima, cargo que divide com Gaio Cecílio Trifeno até que a morte inesperada deste último o faz assumir sozinho todas as atribuições do cargo, a contragosto. O duunvirato, vale acrescentar, foi um cargo político usualmente dividido por duas pessoas, então a escolha da cúpula fugia ao modelo tradicional de governo. Lúcio era um homem cético e, como grande 
Rev. Interd. em Cult. e Soc. (RICS), São Luís, v. 6, n. 1, p. 45- 62, jan.jjun. 2020

ISSN eletrônico: 2447-6498

discípulo de Marco Aurélio, um estoico, o que é, sem dúvida seu traço mais marcante - e mais complexo. Um homem extremamente reto, acredita agir pondo sempre os interesses de seu povo em primeiro plano. O que o duúnviro não vê é que nem todos os interesses romanos são atendidos em sua gestão, o que gera intensa insatisfação popular. Ademais, Lúcio encontra-se cercado por ameaças nos âmbitos externo e interno: no primeiro, o magistrado teme uma invasão moura e toma medidas drásticas para prevenir sua concretização; no segundo, falha em dar a devida atenção ao surgimento de uma seita monoteísta, que pouco a pouco ganha espaço - era a conflagração do cristianismo. Esta última ameaça é envolta por um agravante: o motivo que leva Lúcio a subestimar os fazeres da nova seita podem ser creditados à paixão que nutre por sua líder, Iunia Cantaber, patrícia romana e filha de um importante nobre.

Na obra de Mário de Carvalho, o espaço tem uma expressão peculiar, sobretudo quando expresso pelas vivências do protagonista, que suporta intenso conflito com aspectos culturais considerados essenciais para seu povo; conflitos esses que desencadearão consequências penosas, como o seu exílio. Lúcio é um personagem de grande complexidade quando levamos em consideração se tratar de um homem público. Seu nome remete à luz, iluminação - é também um peixe da água doce - e essa escolha por parte do autor em nada é aleatória. Lúcio é um homem dado aos livros, de grande sabedoria, um erudito, como era costumeiro entre os bem-nascidos. Na fictícia Tarcisis, todos os olhos, patrícios e plebeus, o observam com demasiado interesse, o que faz com que suas ações tenham o poder de levar a província à beira de uma guerra civil. O que merece ser problematizado aqui, inicialmente, é a dimensão de suas atitudes quando guiadas por sua falta de crença em divindades cultuadas na época. Em suma, Lúcio não crê em nada e a romanidade, que acarreta sua religiosidade e tudo o que ela implica, era deixada de lado pelo magistrado no âmbito privado. No âmbito público, Lúcio praticava apenas o mínimo, pelo bem das aparências.

Em numerosas passagens, seu comportamento evidencia o quão deslocado o duúnviro se encontra em sua própria terra e em meio aos seus concidadãos. Levando em conta que todo o romance é uma narração do duúnviro em primeira pessoa, temos acesso privilegiado aos pensamentos, ânsias e conflitos mais íntimos deste personagem e o que percebemos é que Lúcio vive uma espécie de isolamento social com sua esposa Mara: "Não fazia visitas nem recebia visitas. Limitava-me pela alvorada a admitir os clientes (...) e a seguir os preceitos de cidadania que essa circunstância me impunha", diz o duúnviro (CARVALHO, 2006, p. 47). Mara que, muito embora partilhe de suas convicções, faz questão de assinalar a importância de um homem público portar-se como manda o figurino e mostrar- 
Rev. Interd. em Cult. e Soc. (RICS), São Luís, v. 6, n. 1, p. 45- 62, jan./jun. 2020

ISSN eletrônico: $2447-6498$

se cidadão exemplar. Contudo, Lúcio não julga essencial, nem mesmo na sua posição, partilhar de costumes que são tão caros para a sua gente; o magistrado crê que o seu dever deve limitar-se ao exercício do seu ofício com retidão, justiça e honra.

Ao descrever o povo de Tarcisis, o personagem é categórico e deveras crítico em assinalar quais prioridades de seu povo julga frívolas. Segundo ele, na cidade, imperava uma atmosfera despreocupada com questões que se referem ao funcionamento da urbe:

\begin{abstract}
Os mais notáveis nada tomavam a sério; a plebe não tomava a sério os notáveis. E nesta leviana irresponsabilidade, todos se julgavam protegidos por uma grande redoma, diáfana mas sólida, velada por benévolos deuses guardiões. A ninguém ocorria que a divindade do Imperador apenas fosse válida nos templos, que a autoridade do Senado e do Povo apenas fosse garantida pelo acampamento da VII Legião Gémina, a novecentas milhas de distância e que, adentro das próprias muralhas, a corrupção da cizânia já lavrasse (...). (CARVALHO, 2006, p. 29)
\end{abstract}

Este pensamento é determinante na maneira com a qual Lúcio lida com as demandas do povo de Tarcisis: todas as demandas que considera banais são desdenhadas em seu íntimo, algumas até mesmo sequer são atendidas. Este é o caso das celebrações de jogos e combates em arenas. Nos jogos, tão amplamente aceitos e glorificados na Roma antiga, Lúcio apenas consegue enxergar barbárie, desordem e destruição, assim os descrevendo em uma rememoração da ocasião em que conheceu pessoalmente seu mentor ícone estoico, o Imperador Marco Aurélio: "Nestes jogos só vi sangue, mortandade. Nós, os Romanos, proibimos os sacrifícios humanos e, no entanto..." (CARVALHO, 2006, p. 187), reflete o duúnviro acerca das contradições de seu povo, assinalando a hipócrita civilidade praticada por um Império sanguinário.

O que foge à compreensão de Lúcio é justamente o fato de que as peculiaridades que compõem uma cultura pertencem à ordem do coletivo. Logo, não cabe a um homem, mesmo aquele favorecido por uma dada instância de poder, determinar única e isoladamente os ditames socioculturais de uma nação. Aos representantes do poder cabe, unicamente, a preservação de suas tradições, certificando-se de sua continuidade e longevidade. Os romanos que se mantivessem fiéis ao manejo das práticas culturais seriam considerados 'romanizados e felizes" (CARVALHO, 2006, p. 188). Seriam, em outras palavras, considerados romanos de fato, com todas as implicações que sua pátria acarreta.

Este sentido de pertencimento à pátria era notadamente escasso no personagem de Lúcio Valério Quíncio. A complexidade do personagem torna este fato por vezes contraditório: é um homem intensamente guiado pelo senso de dever cívico, no entanto falha em captar a verdadeira dimensão desse dever, que possui desdobramentos que se estendem 
Rev. Interd. em Cult. e Soc. (RICS), São Luís, v. 6, n. 1, p. 45- 62, jan./jun. 2020

ISSN eletrônico: $2447-6498$

também aos aspectos culturais considerados tão caros à cultura romana, mas tão menosprezados pelo magistrado. Este agravante nos leva a crer que a própria falta de apego a sua terra é o fator que molda toda a percepção do magistrado dos espaços de Tarcisis, pois, como afirma Tuan, "a afeição pela pátria é uma emoção humana comum (...). Quanto mais laços houver, mais forte será o vínculo emocional" (2013, p. 194). Suas raízes parecem ser, portanto, enfraquecidas. Tuan acrescenta ainda:

\begin{abstract}
Uma pátria tem seus referenciais, que podem ser marcos de grande visibilidade e importância pública, como monumentos, templos, campos de batalha sagrados ou cemitérios. Esses sinais visíveis servem para aumentar o sentimento de identidade das pessoas; incentivam a consciência e a lealdade para com o lugar. (TUAN, 2013, p. 194 e 195)
\end{abstract}

Sua tão explícita falta de identificação para com o seu povo, sua cultura, assim como seus espaços é tamanha que isto acaba por gerar uma cisão entre aspectos que deveriam caminhar lado a lado no ofício de um magistrado: o dever cívico e o interesse pelo sentir do povo.

Existe um âmbito em especial com o qual o duúnviro lidava com certa perplexidade: o religioso. Os templos são grandes referenciais da cultura romana e, no romance, se fazem absolutamente presentes, com menção a pelo menos três. Em certa passagem, o personagem oferece-nos o relato de uma experiência religiosa sua aos treze anos de idade que muito revela sobre o Lúcio adulto:

\begin{abstract}
Quando, aos treze anos, abandonei bula e pretexta e o meu pai recolheu minha primeira barba, determinou que eu passasse uma noite no santuário de Apolo, então fora da cidade, para que o deus me inspirasse em sonhos. [...] Eu tive alguma dificuldade em adaptar-me à frialdade e ao desconforto do espaço. Enquanto olhei para ela, a estátua do deus não deixou de ser pedra. Fui fechando os olhos, vencido pelo cansaço, e acabei por dormir a sono solto. Não sonhei com nada. (CARVALHO, 2006, 105)
\end{abstract}

O espaço sagrado, a exemplo de santuários e templos, define Rosendahl, é "um campo de forças e de valores que eleva o homem religioso acima de si mesmo, que o transporta para um meio distinto daquele no qual transcorre sua existência” (2012, p. 76). Tais colocações não poderiam estar mais distantes do que experienciam o jovem e o adulto Lúcio, já que a passagem revela que aos treze anos Lúcio já cultivava o espírito cético da vida adulta: "O sagrado manifesta-se sempre como uma realidade inteiramente diferente das realidades "naturais"”, acrescenta Eliade (2008, p. 16). O discurso do protagonista revela uma completa ausência de crença em poderes de divindades, no sagrado que ali se manifesta, na medida em 
Rev. Interd. em Cult. e Soc. (RICS), São Luís, v. 6, n. 1, p. 45- 62, jan./jun. 2020

ISSN eletrônico: $2447-6498$

que, durante sua estadia no santuário, não vivenciou qualquer hierofania de forma ativa. No entanto, na mesma ocasião, o escravo que o acompanhava relatou ter tido a visão de uma manifestação divina de Apolo na qual o deus contemplava o jovem Lúcio. O então adolescente manteve-se incrédulo dos acontecimentos que o envolviam.

Outro ponto interessante a ser salientado em referência à mesma passagem é o fato de o jovem Lúcio exprimir certa passividade diante de sua ida ao santuário, como se esperasse que a fé o atingisse como um raio ao acaso, comportamento que se mantém até a vida adulta. Sua percepção do santuário como espaço é vazia de significado, pois ali não experienciou sua religiosidade positivamente, ou mesmo, ativamente. Sobre isto, Tuan afirma que, "para experienciar no sentido ativo, é necessário aventurar-se no desconhecido e experimentar o ilusório e o incerto" (2012, p. 18).

Lúcio jamais cultuou genuinamente os deuses romanos, e este fato reconfigura de forma decisiva sua percepção dos espaços sagrados, assim como da própria religião romana. O santuário é para Lúcio um espaço destituído de qualquer valor de ordem simbólica, religiosa ou espiritual, o que encontra justificativa no fato de sua experiência do sagrado ser igualmente destituída de significância. Encontramos reverberação em Tuan quando afirma que "a religião tanto pode vincular uma pessoa ao lugar como libertá-la dele. O culto aos deuses locais vincula um povo ao lugar [...]” (2013, p. 186).

Em outra de suas reflexões sobre o sagrado, Lúcio, em função dos eventos decorridos do suicídio de Pôncio, e lentamente perdendo estima da plebe e dos patrícios, pondera passar uma noite no templo para "tirar partido de uma exibição pública de piedade" (CARVALHO, 2006, p. 105):

\begin{abstract}
Não que o ambiente sagrado pudesse libertar-me da minha amargura. O que era o templo? Quatro paredes geladas, colunas, escuridão, algumas estátuas. E quem, no íntimo, acreditava naqueles deuses, além dos escravos e da plebe lábil? Mas se uma noite no templo não apaziguaria os deuses, porque não ofendidos, nem me poria de bem comigo, porque o meu estado de espírito não dependia do lugar de pernoita, talvez pudesse reconciliar-me com a cidade. Politicamente útil. (CARVALHO, 2006, 105)
\end{abstract}

Discrepante das colocações de Chevalier e Gheerbrant no Dicionário de Símbolos, para quem "o templo é um reflexo do mundo divino" (2018, p. 874), Lúcio não reconhece a sacralidade do templo, o que pode ser evidenciado pela maneira como descreve o dito espaço, de forma impessoal e quase clínica, como a citar um espaço qualquer, um espaço profano, cotidiano. O espaço sagrado, portanto, jamais adquire a configuração de lugar para Lúcio, uma vez que "os lugares são centros aos quais atribuímos valor” (TUAN, 2013, p. 12). 
Rev. Interd. em Cult. e Soc. (RICS), São Luís, v. 6, n. 1, p. 45- 62, jan./jun. 2020

ISSN eletrônico: 2447-6498

Contudo, Lúcio é um homem reto e, como tal, se "sentia obrigado a, por normas não escritas, mas acessíveis a todos os homens de bem, a respeitar os limites do meu decoro íntimo" (CARVALHO, 2006, p. 107).

Como então definir a relação do personagem com o espaço agora dessacralizado? Retornemos, então, a Tuan e a seus conceitos de apinhamento e espaciosidade. Antitéticos por definição, o que os difere tem muito menos relação com o tamanho do espaço e muito mais com o grau de liberdade nele experienciado. Espaciosidade, sugere o geógrafo, "está intimamente associada com a sensação de ser livre [...] a capacidade para transcender a condição presente" (2013, p. 70). O apinhamento não apenas implica uma falta de liberdade, como também pode ser motivado por atividades conflituosas, como é o caso de Lúcio. O personagem pondera utilizar-se dos templos não por sua sacralidade ou possibilidade de manifestação do divino, mas por pura manobra política, como evidenciado na passagem acima. $\mathrm{O}$ desconforto vivenciado por ele, as paredes geladas, a escuridão, tudo converge para a interpretação: Lúcio se sente apinhado em templos e santuários, na medida em que não considera que tais espaços possuam configuração de lugar, pois carecem de experiências positivas que os validem como tais.

A experiência do sagrado $^{7}$ pelo personagem naturalmente se expande para os âmbitos político e social. Naquela época, a expressão da religião romana era parte crucial de sua cultura. Sobrepujar as tradições de seu povo tem como consequência o enfraquecimento de suas relações com toda a província de Tarcisis, causando o seu exílio. Sobre o vínculo entre terra e religião na antiguidade, Tuan coloca que "o exílio era o pior dos destinos, pois não apenas privava o homem de seus meios materiais de subsistência, como também da sua religião e proteção das leis garantidas pelos deuses locais" (2013, p. 188). Nessa perspectiva, o duúnviro não teve que abrir mão de tanto, uma vez que as leis dos deuses não the eram aplicáveis. Seu vínculo com Tarcisis era, portanto, frágil, já que carecia de valor e significado.

Some-se a todos esses agravantes aquele que é, possivelmente, o pior: Lúcio ignora os rituais da congregação do peixe e falha em conter a seita que desafia os preceitos da romanidade. A perseguição ao grupo de cristãos, naturalmente, tem clamor de absolutamente todas as esferas sociais, do populacho ao senado. O súbito e indomável enamoramento de

\footnotetext{
${ }^{7}$ Em outra ocasião, o duúnviro visita um templo para a realização do ritual de confirmação como duúnviro após a morte de Trifeno. Na cerimônia, é realizado um sacrifício, do qual o magistrado delega por não gostar de sangue. A experiência prova-se um misto de aversão e tédio com menções a "cantarias escurecidas do templo", "uma grossa mancha de umidade" nas paredes do templo frio e escuro. "Tudo isto, em si, não tinha grande importância. Tratava-se apenas dum rito, dum simulacro, de gestos consagrados", conclui. (CARVALHO, 2006, p. 43 e 44$)$
} 
Rev. Interd. em Cult. e Soc. (RICS), São Luís, v. 6, n. 1, p. 45- 62, jan./jun. 2020

ISSN eletrônico: 2447-6498

Lúcio pela patrícia - e líder da seita - Iunia Cantaber confunde o seu juízo e abranda seu senso de justiça.

O que Lúcio falha miseravelmente em aprender é a real dimensão de suas obrigações. Ao isolar-se do convívio social, não promover os jogos nas arenas, não praticar o culto aos deuses e priorizar seu dever cívico de forma radical, ele se distancia do que julga preservar: a romanidade. Trazemos, então, certa passagem em que o personagem descreve a si mesmo, assinalando as virtudes que são determinantes do seu caráter e de suas ações:

\footnotetext{
Sou um senhor da terra, sou um romano, leio, cultivo-me, marco os tempos com o meu porte, os meus gestos, os meus ditos, as minhas maneiras, a minha fleuma, o meu trajo togado. Dignidade. Gravidade. Romanidade. Humanidade. Convulsos temores e angústias resolvam-nos as legiões, e de rijo, que é o que lhes compete. A mim, agora, os livros... (CARVALHO, 2006, p. 14, grifo nosso)
}

Lúcio aponta, em períodos separados, os princípios que considera indispensáveis não apenas para o exercício de seu ofício, mas para a sua vida: ser digno, honrado e nobre, o que pressupõe ser justo; agir com gravidade e sobriedade; agir em concordância com os preceitos e ditames da cultura romana; e, talvez, a virtude mais emblemática e norteadora do seu fazer, a humanidade, que assegura sua benevolência para com os seus iguais. E por "iguais" compreendamos todos os cidadãos da urbe, sem distinção de classe ou orientação ideológica. Isto faz com que se instaure um grave problema: Lúcio, ao contrário de seus concidadãos, não é tão rápido em julgar a congregação do peixe e seus valores. Ele tenta, antes de tudo, compreendê-los.

Os protestos, e consequente rejeição a Lúcio por parte dos habitantes de Tarcisis, sobretudo os patrícios e posteriormente a plebe, têm como fio condutor as seguintes questões: como pode um romano, um verdadeiro romano, não mostrar apreço por tantos aspectos considerados vitais em sua cultura? Como sobrepujar o sentimento de coletividade no exercício de um cargo público em que o povo e a sua vontade deveriam reinar protagonistas? O Imperador Marco Aurélio bem tentou instruí-lo quando disse: "nunca demonstres, por actos ou omissões, que estás longe do sentir do povo. Poderias romper um equilíbrio fixado na ordem natural das coisas em que as tuas convicções interviriam como um mero capricho pessoal, alheio e perturbador" (CARVALHO, 2006, p. 188). Aos olhos de Tarcisis, foi precisamente o contrário que Lúcio fez, repetidas vezes: deixou de lado a romanidade de que julgavam partilhar. De fato, Lúcio não se envolvia nas questões do povo, o que em diversas passagens fica evidenciado pela sua falta de conhecimento da cidade, de suas ruas estreitas, de seus habitantes: “Um outro dever do homem público", avisa Marco Aurélio, "é saber tudo o 
Rev. Interd. em Cult. e Soc. (RICS), São Luís, v. 6, n. 1, p. 45- 62, jan./jun. 2020 ISSN eletrônico: $2447-6498$

que se passa à sua volta" (CARVALHO, 2006, p. 189). O seguinte diálogo entre Lúcio e o senador Calpúrnio esclarece:

- Dizem-me que estás a isolar-te dos nossos concidadãos. Não recebes os clientes, incompatibilizas-te com a cúria, não frequentas as termas, nem o triclínio dos outros...

- Não tenho tempo nem disposição. (...) Não me parece a altura para cumprir vida social...

(...)

- Mas sabes, Lúcio?, é precisamente nos momentos atribulados que a afirmação da romanidade é mais urgente. O povo tem que estar unido em volta de chefes em que se reconheça.

(...)

- Os assuntos da cidade corriam melhor se eu perdesse tempo a receber os clientes, a distribuir espórtulas, a presidir a jogos, a passar os serões em ceias?

- Apenas farias o que esperam de ti! Lúcio, meu caro Lúcio, tu tens sido visto a deslocar-te a pé! E, às vezes, sozinho! - e perguntou-me de chofre: - Quem ganhou a última corrida nas calendas passadas? Os azuis ou os verdes? Os brancos ou os vermelhos? (...) Como se chama o mais glorioso auriga dos azuis? (...) Ah, não sabes nada disto, Lúcio...

- Nem quero saber. Não me parece importante. De resto... Sou como sou.

- E o povo é como é. E está inquieto e dividido. Murmura-se. Conspira-se. (...) (CARVALHO, 2006, p. 192 e 193)

Nesta perspectiva, nos cabe introduzir a noção de lugar-sem-lugaridade ou placelessness. $\mathrm{O}$ conceito foi cunhado por Relph e refere-se à "ausência da capacidade de lugaridade, ou seja, da constituição de lugar”, comentado por Marandola Jr., que, em seguida, complementa:

\begin{abstract}
A lugaridade (qualidade própria de lugar) se funda nos seus aspectos constitutivos (como a autenticidade, o encontro, o sentido de lugar, o espírito do lugar entre outros), sendo melhor entendida enquanto uma gradação, tendo níveis em contextos diferentes. Lugares autênticos seriam aqueles com forte lugaridade, enquanto os não lugares e os placelessness seriam aqueles que possuem ausência de lugaridade, ou seja, lugares-sem-lugaridade. (2014, p. 25)
\end{abstract}

Esta é Tarcisis (e, por que não, Roma?) aos olhos de Lúcio Valério Quíncio. Suas experiências na cidade, no seu ofício e junto a "seu" povo assinalam uma configuração que em muito destoa da de seus concidadãos. Lúcio encontra-se profundamente deslocado, não apenas nos entornos da urbe, mas em sua própria cultura, um tanto mais abrangente. Não consegue encontrar lugaridade na romanidade. No tempo presente da narrativa, ao qual temos breve acesso no início e ao final do romance, Lúcio encontra-se exilado e em busca de sentido. Foi preciso sair de sua cidade para que adquirisse perspectiva suficiente para olhar de fora e compreender o que lhe sucedeu. Seria o começo de seu encontro consigo próprio? Sanadas as questões do passado, seria ele capaz de encontrar, finalmente, o seu lugar? Estar 
Rev. Interd. em Cult. e Soc. (RICS), São Luís, v. 6, n. 1, p. 45- 62, jan./jun. 2020 ISSN eletrônico: 2447-6498

fora é seu consolo, e este fato parece finalmente possibilitar seu encontro com a tão desejada paz em uma situação que lhe foi imposta: o exílio: "Inquietou-me, é verdade, o pequeno escravo que desenhava um peixe, na areia, outro dia. Hoje sinto-me tranquilo, de novo. Afinal, o rapaz não sabia que sinal era aquele. Nunca ouviu, nem ouvirá, decerto, mencionar o deus que passeava no jardim, pela brisa da tarde", conclui o magistrado (CARVALHO, 2006, p. 319). Em entrevista ao jornal "Público", Mário de Carvalho afirma sobre o personagem: "a sua inteligência permite-lhe cheirar a mudança, a sua rectidão torna-o inepto para sobreviver ao processo" (1995, p. 32). Eis a causa de seu insucesso na vida política: era um homem demasiado correto. A crítica carvalheana da subversão dos ideais é inclemente e, lamentavelmente, verdadeira, mesmo nos dias atuais, o que, na obra, anuncia a decadência dos tempos dourados do grande Império.

\section{CONSIDERAÇÕES FINAIS}

Mário de Carvalho é autor de obra extensa e versátil, escolha ideal para abrilhantar as investigações a que nos propusemos. O romance em tela se provou bastante fecundo no cumprimento de alguns propósitos suscitados neste trabalho: elucidar como se dão as relações homem-lugar no romance Um deus passeando pela brisa da tarde, no contexto do surgimento de uma nova seita em pleno apogeu romano e compreender como se afiguram os fenômenos da religiosidade e da romanidade no protagonista, assinalando nos seus conflitos as nuances psicológica e simbólica, desencadeadas pelos sentimentos atribuídos aos seus entornos; paralelamente, buscou-se a difusão das possibilidades de estudo acerca do espaço na obra carvalheana e, quem sabe assim, despertou-se também o interesse pela leitura do referido autor. Mário materializa hábitos com a destreza de um observador sagaz do mundo em volta, reportando-se a tempos remotos para lançar luz sobre temas absolutamente atemporais. Tratase de um romance histórico, decerto. Mas as vozes que dele ressoam são demasiado claras aos leitores de nossos dias. Sem levantar a bandeira de um falso moralismo, Mário de Carvalho faz denúncias no tocante à hipocrisia das práticas estoicas que apenas funcionam nos livros de filosofia e a intolerância dos cristãos, tão presente no evangelho.

A partir dos estudos da Geografia Humanista Cultural, pretendemos lançar luz sobre os aspectos subjetivos da experiência que operam uma influência direta na percepção que Lúcio Valério tem de seu entorno ficcional, isto é, a diversidade de experiências do sujeito é capaz de reconfigurar relações e espaços. A abordagem geográfico-cultural oferece 
Rev. Interd. em Cult. e Soc. (RICS), São Luís, v. 6, n. 1, p. 45- 62, jan./jun. 2020 ISSN eletrônico: 2447-6498

um prisma de natureza ontológica para a compreensão do espaço, sendo, assim, inconcebível uma topoanálise que não evidenciasse a essência subjetiva dos seres que habitam o espaço.

Lúcio não vivencia a religiosidade romana, o que repercute negativamente em suas relações com o povo de Tarcisis e coloca em xeque sua permanência na província. Adepto da prática do estoicismo, vê em seu ídolo o imperador que infringe a própria doutrina em prol do bem-estar coletivo. Lúcio, no entanto, não é capaz de fazer o mesmo; sua retidão o impede. Neste ínterim, encontra-se perdidamente apaixonado pela líder cristã, que lhe desperta o fascínio de um engajamento religioso que jamais teve. $O$ personagem não encontrou lugaridade nos espaços sagrados, sendo eles grandes protagonistas da cultura do Império Romano. O exílio é o seu destino. Contudo, seria o exílio de todo ruim numa terra destituída de valor simbólico? Ao final do romance, temos a visão de um protagonista exilado em paz consigo e com seu entorno. Ao que parece, Lúcio é capaz de encontrar enraizamento em qualquer lugar e em lugar nenhum. Ou, ao que tudo indica, sua lugaridade reside no próprio exílio. Como não praticante rigoroso da romanidade, Lúcio vivencia um exílio atípico. Não é feliz e tampouco sofre, mostrando-se, assim, fiel ao imperturbável estoicismo; antes, está em paz. Vivencia o tão prezado estado de inércia do qual fora tirado quando se iniciam os conflitos narrados. Poderia ser ele mesmo o deus a passear no jardim pela brisa da tarde.

\section{REFERÊNCIAS}

BACHELARD, Gaston. A poética do espaço. Trad.: Antonio de Pádua Danesi - $2^{\mathrm{a}}$ ed. São Paulo: Martins Fontes, 2008.

CARVALHO, Mário de. Um deus passeando pela brisa da tarde. São Paulo: Companhia das Letras, 2006.

CHEVALIER, Jean. GHEERBRANT, Alain. Dicionário de símbolos: mitos, sonhos, costumes, gestos, formas, figuras, cores, números. Coord.: Carlos Sussekind; Trad.: Vera da Costa e Silva [et al.]. 31 a ed. - Rio de Janeiro: José Olympio, 2018.

DARDEL, Eric. O Homem e a Terra: natureza da realidade geográfica. Trad.: Werther Holzer. São Paulo: Perspectiva, 2015.

ELIADE, Mircea. O sagrado e o profano. Trad.: Rogério Fernandes. São Paulo: Martins Fontes, 2008.

FERRAZ, Cláudio Benito Oliveira. Literatura e espaço: aproximações possíveis entre Arte e Geografia. In: SOUZA, A. de O. [et. al.]. Transfazer o espaço: ensaios de como a literatura vira espaço e vice versa. Dourados: Ed. UFGD, 2011. 
Rev. Interd. em Cult. e Soc. (RICS), São Luís, v. 6, n. 1, p. 45- 62, jan./jun. 2020 ISSN eletrônico: 2447-6498

ISKANDAR, Jamil Ibrahim; LEAL, Maria Rute. Sobre positivismo e educação. Revista Diálogo Educacional, v. 3, n. 7, 2002, p. 89-94.

MARANDOLA JR., Eduardo; OLIVEIRA, Lívia de. Geograficidade e espacialidade na Literatura. Geografia, Rio Claro, v. 34, n. 3, set/dez. 2009. p. 487 - 508.

MARANDOLA JR., Eduardo; HOLZER, Werther; OLIVEIRA, Lívia de (Orgs). Qual o espaço do lugar?: Geografia, epistemologia, fenomenologia. São Paulo: Perspectiva, 2014. MENDES, Pedro Rosa. Que sirva de lição a quem o ler. Público. Portugal: 18 de julho de 1995. Disponível em: < https://tinyurl.com/y7yu2f39> Acesso em: 20 de maio de 2018.

RELPH, Edward. Reflexões sobre a emergência, aspectos e essência de lugar. In: MARANDOLA, Eduardo Jr. HOLZER, Werther. OLIVEIRA, Lívia de (Orgs.). Qual o espaço do lugar?: Geografia, epistemologia, fenomenologia. São Paulo: Perspectiva, 2014.

ROSENDAHL, Zeny. O sagrado e sua dimensão espacial. In: CASTRO, Iná Elias de; GOMES, Paulo Cesar da Costa; CORREAA, Roberto Lobato (Org.). Olhares geográficos: modos de ver e viver o espaço. Rio de Janeiro: Bertrand Brasil, 2012.

SARAMAGO, Ligia. Como Ponta de Lança: o pensamento do lugar em Heidegger. In: MARANDOLA, Eduardo Jr. HOLZER, Werther. OLIVEIRA, Lívia de (Orgs.). Qual o espaço do lugar?: Geografia, epistemologia, fenomenologia. São Paulo: Perspectiva, 2014.

TUAN, Yi-Fu. Topofilia: um estudo da percepção, atitudes e valores do meio ambiente. Trad.: Lívia de Oliveira. Londrina: Eduel, 2012.

Espaço e lugar: a perspectiva da experiência. Trad.: Lívia de Oliveira. Londrina: Eduel, 2013. 